Research Article

\title{
Shear Properties and Mechanism of Freeze-Thaw Interface in Unsaturated Coarse-Grained Soil from Qinghai-Tibet Plateau
}

\author{
Yonglong Qu $\left(\mathbb{D},{ }^{1,2}\right.$ Wankui Ni $\left(\mathbb{D},{ }^{2}\right.$ Fujun Niu $\mathbb{D D}^{3}{ }^{3}$ Yanhu Mu $\mathbb{D}^{3},{ }^{3}$ Jing Luo $\mathbb{D}^{3},{ }^{3}$ and Hui He \\ ${ }^{1}$ School of Civil and Architecture Engineering, Xi'an Technological University, Xi' an 710021, China \\ ${ }^{2}$ College of Geology Engineering and Geomatics, Chang' an University, Xi' an 710054, China \\ ${ }^{3}$ State Key Laboratory of Frozen Soil Engineering, Northwest Institute of Eco-Environment and Resources, \\ Chinese Academy of Sciences, Lanzhou 730000, China \\ Correspondence should be addressed to Yonglong Qu; quyl2018@163.com and Yanhu Mu; muyanhu@lzb.ac.cn
}

Received 30 November 2020; Revised 23 January 2021; Accepted 19 February 2021; Published 2 March 2021

Academic Editor: Junping Ren

Copyright ( 2021 Yonglong Qu et al. This is an open access article distributed under the Creative Commons Attribution License, which permits unrestricted use, distribution, and reproduction in any medium, provided the original work is properly cited.

\begin{abstract}
Freeze-thaw interface in unsaturated coarse-grained soil (CGS) is a weak plane which can cause slope failures in cold regions. This study presents a series of large-scale direct shear tests on freeze-thaw interface in CGS through a temperature control system. The tested soil was taken from a high slope in the Qinghai-Tibet Plateau. It was remolded with three dry densities $(1.9,2.0$, and 2.15 g/ $\left.\mathrm{cm}^{3}\right)$ and three moisture contents $(9.0 \%, 11.5 \%$, and $14.0 \%)$. With testing results, direct shear curves mainly performed as hardening deformation, and they were affected considerably by specimen conditions. The shear strength increased with both the increasing dry density and normal stress, but it was opposite with moisture content changed. The cohesion and internal friction angle increased with the increase in dry density but decreased with the moisture content. The particle movement and water migration of freeze-thaw interface in CGS during the test were significant, and they had close relations with the shear properties of specimens. And, an empirical model was produced to express the effect of pore ice on the shear strength of interface during the shear test. The tests and analysis in this study may provide useful references for CGS slope stability analysis in high cold regions.
\end{abstract}

\section{Introduction}

In cold regions, either freezing or thawing process, water migration always occurs near the freeze-thaw interface of soils $[1,2]$. It would result in the increase in the moisture content of interface and further reduces the effective stress of soil $[3,4]$. As a result, the freeze-thaw interface of soil is a weak plane of slopes owing to the reduction of the soil strength, which is easy to induce slope failure and other geological hazards $[5,6]$. Landslides that occur in the springthawing season usually have a close relationship with the freeze-thaw interface $[7,8]$. The Yigong catastrophic landslide (April, 2000) is a typical representative of such slope failure [9].

Previous studies on the freeze-thaw interface mainly focus on the detection and prediction of the depth of freezethaw interface in shallow ground, including the freezing depth and active layer thickness [10-12]. However, few studies on the strength of freeze-thaw interface have been reported. Xu et al. [13] observed that the strength of freezethaw interface is between the frozen and thawed soil, and the long-term strength is relatively low. Given the different freezing points of pure and salt water, Cheng et al. [14] designed a freeze-thaw interface and proposed that the modified coefficient of the shear strength of interface could be taken as 0.946. Cheng et al. [5] and Ge et al. [15] found that the freeze-thaw interface constitutes the weak interface of landslide hazard and affects the critical depth of slip surface of soil slope. Gao et al. [16] performed a series of small-scale direct shear tests on the ice-soil interface of finegrained soil. The results showed that the strength of interface in silt soil is larger than that of the thawed one, and the sliding slope will be in the thawed soil layer above the interface, whereas the case is the opposite for clay soil.

As a natural material, the coarse-grained soil (CGS) is widely distributed on mine dumps and mountain slopes in 
high-cold regions, and it is also widely used in Earth dams and roadbed filling [17]. The freeze-thaw sensitivity of soils has great effect on the slope stability and normal operation of infrastructures in cold regions $[2,8]$. It has been confirmed that the properties of CGS are sensitive to the freezing and thawing when it contains fine particles [18]. Further, Wang et al. [19] determined the critical fine content of the freezethaw sensitive CGS. Beier and Sego [20] found that the freezing and thawing enhance the strength and surface stability of loose and supersaturated coal tailing, but it was the opposite for the dense and unsaturated soils [21, 22]. For the effect of temperature on the properties of CGS, Lai et al. [6] observed that the mechanical properties of soil near the freeze point exhibit strongly stochastic properties. And Wang et al. [23] deemed that the shear strength of thawed CGS is significantly smaller than that of the frozen one. Considering the effect of cyclic freeze-thaw, Liu et al. [24] and $\mathrm{Qu}$ et al. [22] discovered the strength and modulus of sands decrease and then change slightly. Moreover, large equipment is often needed to investigate the mechanical properties of CGS $[25,26]$.

However, there are rare reports on the mechanical properties of freeze-thaw interface in CGS containing fine particles, which are crucial to the CGS slope stability and the operation of infrastructure in cold regions. In view of the size effect of CGS and the special shear plane, a series of large-scale direct shear tests would be conducted on the shear strength of the freeze-thaw interface in CGS by a temperature-controlled apparatus, to investigate the mechanical properties of freeze-thaw interface in CGS affected by the moisture content $(w)$, dry density $\left(\rho_{\mathrm{d}}\right)$, and normal stress $(\sigma)$.

\section{Materials and Methods}

2.1. Material Properties. The tested soil used in this study was collected from a high-altitude mine dump in a metal mine in the Qinghai-Tibet Plateau (N 29 $42^{\prime} 29.12^{\prime \prime}$, E $91^{\circ} 46^{\prime} 10.53^{\prime \prime}$ ) as shown in Figure 1. The natural soil moisture content was $11.5 \%$. Through the sieving method, the grainsize distribution of tested soil is shown in Figure 2. According to the results, the soil was classified as coarsegrained soil (CGS) based on the Chinese National Standard: Standard for Geotechnical Testing Method (GB/T 501232019) and Specification of Soil Test (SL237-1999). According to the test results of the standard proctor test, the maximum dry density and optimum moisture content were $2.17 \mathrm{~g} / \mathrm{cm}^{3}$ and $9.1 \%$, respectively. The physical properties of the tested soil are listed in Table 1.

2.2. Large-Scale Direct Shear Apparatus. The large-scale direct shear test system (TZJ-150) applied in this study is a temperature-controlled apparatus, as shown in Figure 3. The horizontal and vertical pressures are driven by two stepper servo motors with maximum outputs of $150 \mathrm{kN}$ and $100 \mathrm{kN}$, respectively. The pressure and displacement of each motor can be precisely controlled by the feedback control module, and the loading speed ranges from 0.002 to $20 \mathrm{~mm} / \mathrm{min}$. The

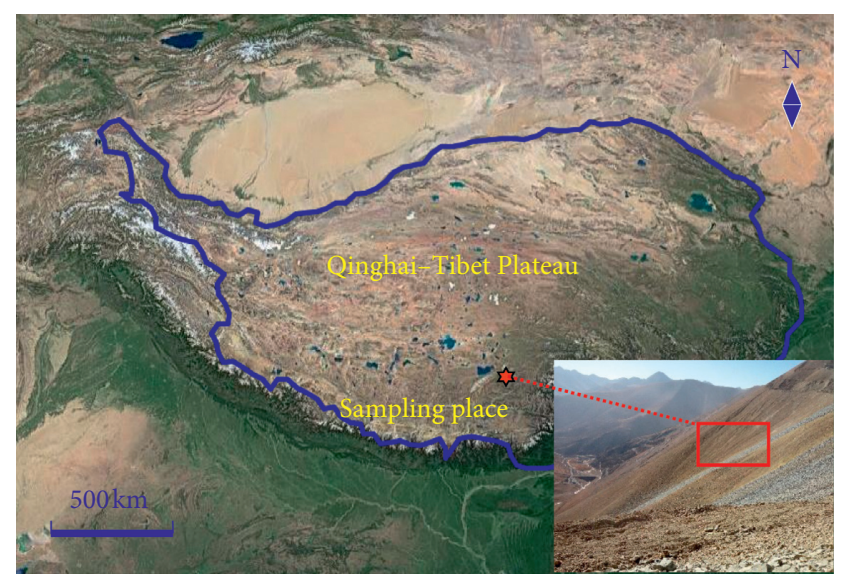

FIgure 1: Sampling place in Qinghai-Tibet Plateau.

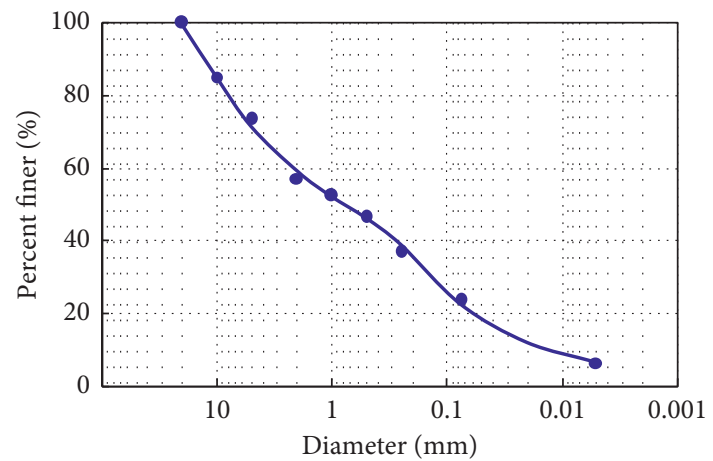

Figure 2: Grain-size distribution of the soil used in the tests.

shear box $(300 \mathrm{~mm} \times 300 \mathrm{~mm} \times 200 \mathrm{~mm})$ has a steel structure that supplies a space for coolant inside and has insulation layers outside to reduce cold energy loss. Two cooling bath circulators connected to the upper and lower shear boxes can conduct the cooling process and temperature control independently. Thus, the testing apparatus can ensure the realization of freeze-thaw interface in soil specimens.

2.3. Tested Methods. Considering the physical properties of tested soil and the in-situ slope state, the soil was remolded with three dry densities $\left(\rho_{\mathrm{d}}=1.9,2.0,2.15 \mathrm{~g} / \mathrm{cm}^{3}\right)$ and three moisture contents $(w=9.0 \%, 11.5 \%, 14.0 \%)$. The tested soil was initially mixed with the targeted moisture content by weight and then kept for $6 \mathrm{~h}$ without evaporation. Afterward, the soil was filled into the shear box with three layers to make the soil reach the targeted dry density value. A series of temperature sensors (Platinum thermistor, PT100) was buried at $0.25,0.50$, and 0.75 times the specimen height to monitor the temperature of the tested specimen (Figure 4(a)). A gap with a height of $5 \mathrm{~mm}$ was placed between the two boxes to minimize the effect of the rigid shear box constraint and particle breakage. The cooling bath circulator connected to the lower shear box started at a temperature of $-5^{\circ} \mathrm{C}$. When the temperature of the shear 
TABle 1: Physical parameters of tested soil.

\begin{tabular}{|c|c|c|c|c|c|c|}
\hline \multirow{2}{*}{ Properties } & \multirow{2}{*}{$\begin{array}{l}\text { Natural moisture } \\
\text { content }(\%)\end{array}$} & \multirow{2}{*}{$\begin{array}{l}\text { Saturated moisture } \\
\text { content }(\%)\end{array}$} & \multirow{2}{*}{$\begin{array}{l}\text { Optimum moisture } \\
\text { content }(\%)\end{array}$} & \multirow{2}{*}{$\begin{array}{l}\text { Maximum dry density } \\
\left(\mathrm{g} \cdot \mathrm{cm}^{-3}\right)\end{array}$} & \multicolumn{2}{|c|}{$\begin{array}{l}\text { Fine particles ( } d \\
\leq 0.075 \mathrm{~mm})\end{array}$} \\
\hline & & & & & $\begin{array}{c}\text { Plastic limit } \\
(\%)\end{array}$ & $\begin{array}{c}\text { Liquid limit } \\
(\%)\end{array}$ \\
\hline Values & 11.5 & 14.7 & 9.1 & 2.17 & 14.3 & 28.2 \\
\hline
\end{tabular}

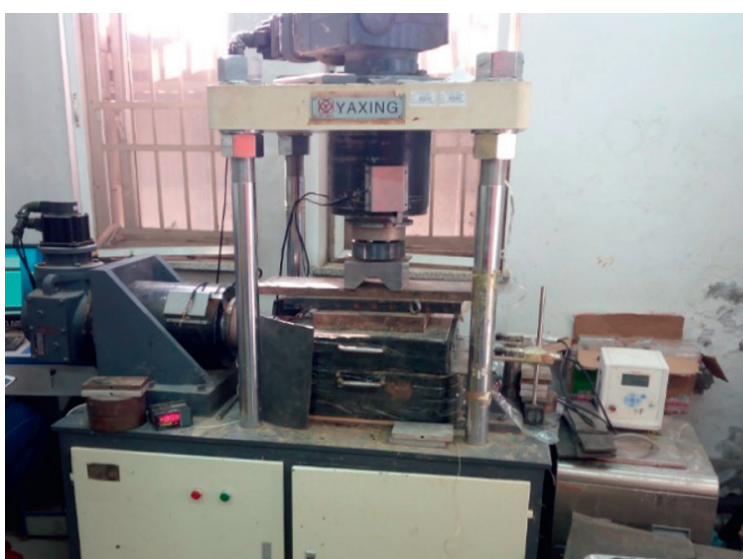

(a)

Figure 3: The large-scale direct shear test system (TZJ-150). (a) The test apparatus picture. (b) The test structural diagram.

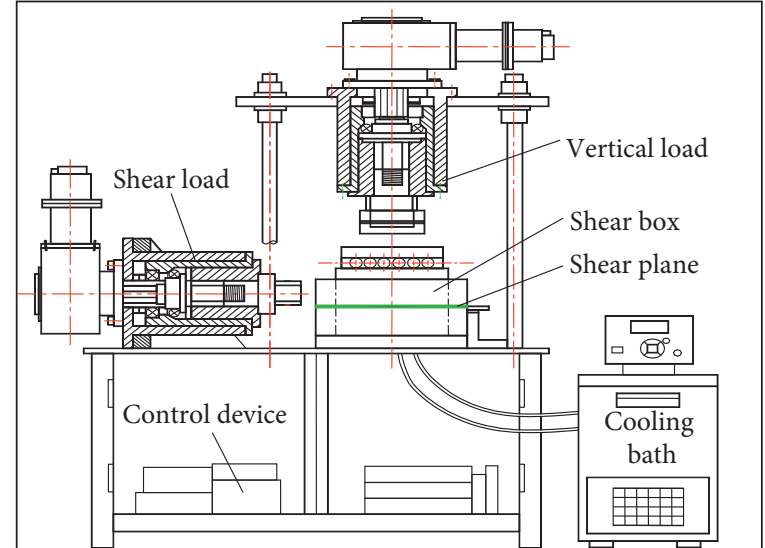

(b)

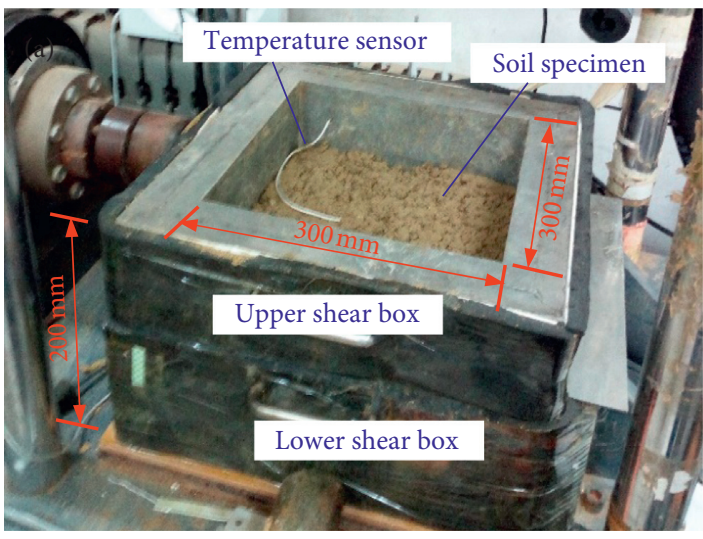

(a)

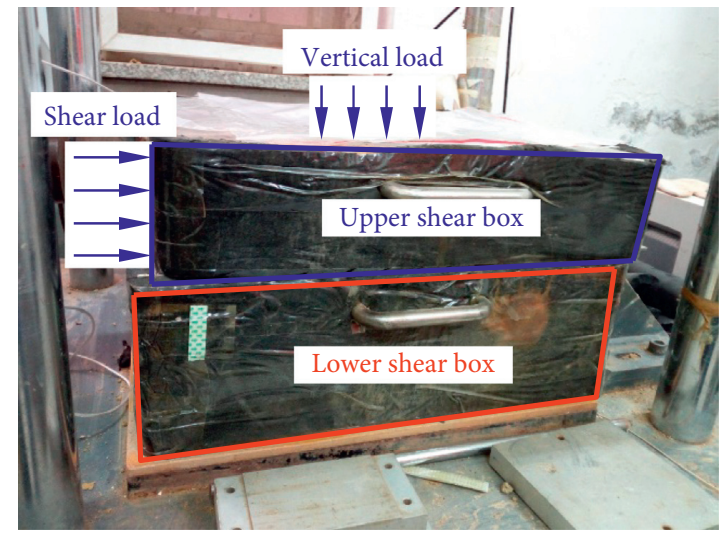

(b)

FIgURE 4: The specimen preparation and shear box. (a) Soil specimen preparation. (b) Shear box after direct shear test.

plane (i.e., half of specimen height) reached $0^{\circ} \mathrm{C}$, a steady normal stress of 200,300 , and $400 \mathrm{kPa}$ was provided. Then, the shear box at a speed of $10 \mathrm{~mm} / \mathrm{h}$ was pushed (Figure 4(b)) [27]. During shearing, the soil in the upper box was kept thawed, whereas that in the bottom box was kept frozen. After each test, three positions (upper box, shear plane, and lower box) were selected to acquire the average moisture content. Three different specimens were used to represent one case, and their average was considered to represent the result of one specimen to ensure reliability.

\section{Results and Analysis}

\subsection{Features of Shear Deformation of Freeze-Thaw Interface}

3.1.1. Features of Direct Shear Curves. As shown in Figure 5, the relationships between shear stress $(\tau)$ of the freeze-thaw interface and shear displacement $\left(\delta_{h}\right)$ mainly performed as hardening deformation. At the beginning, the shear stress increased significantly, but the shear displacement was almost constant. Then, the shear stress increased nonlinearly and the specimens exhibited plastic deformation. With the shear 


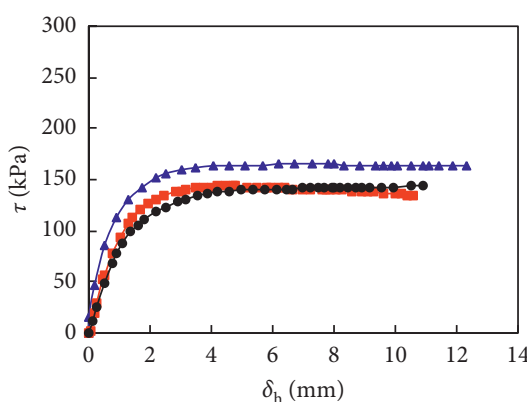

$\simeq \quad$ Moisture content of $9.0 \%$

$\rightarrow$ Moisture content of $11.5 \%$

- Moisture content of $14.0 \%$

(a)

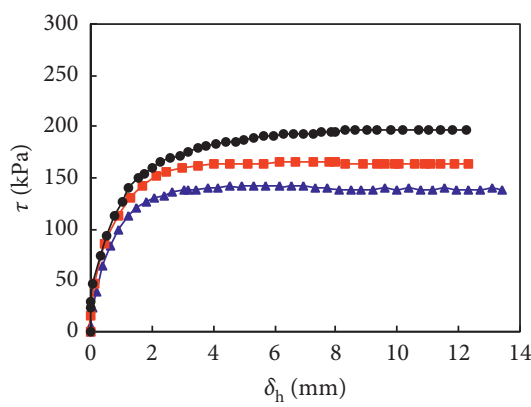

— Dry density of 1.9

- Dry density of 2.0

- Dry density of 2.15

(d)

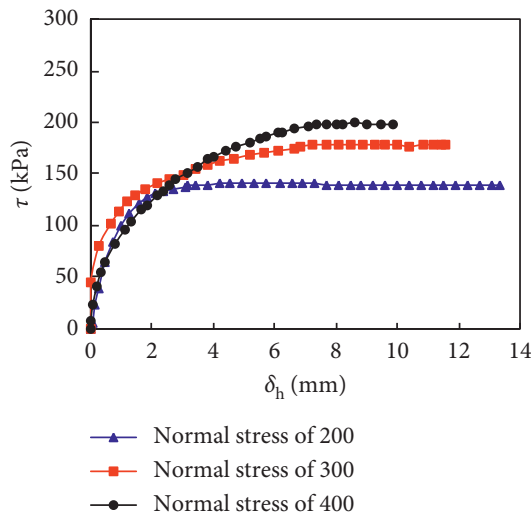

(g)

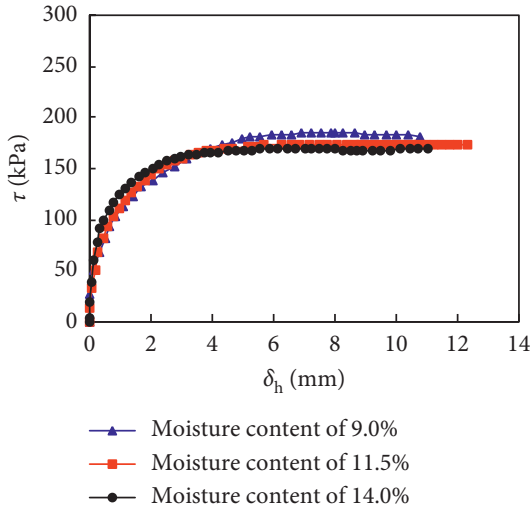

(b)

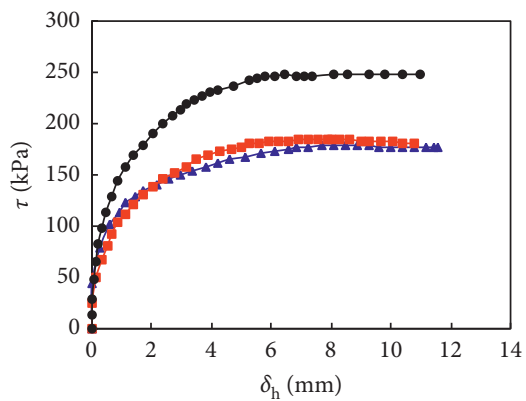

$\longrightarrow$ Dry density of 1.9

$\rightarrow$ Dry density of 2.0

—D Dry density of 2.15

(e)

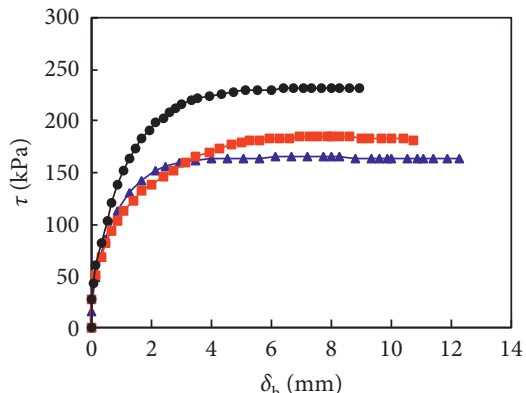

$\rightarrow$ Normal stress of 200

$\rightarrow$ Normal stress of 300

$\rightarrow$ Normal stress of 400

(h)

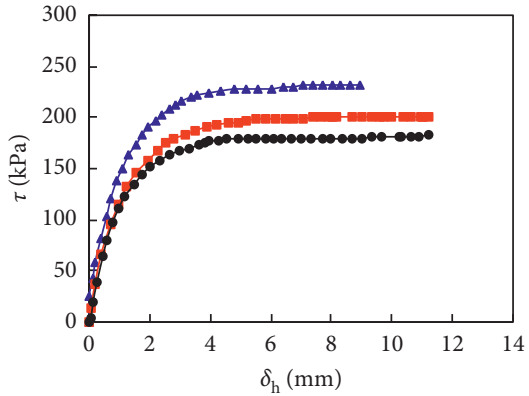

—— Moisture content of $9.0 \%$

$\rightarrow-$ Moisture content of $11.5 \%$

$\longrightarrow$ Moisture content of $14.0 \%$

(c)

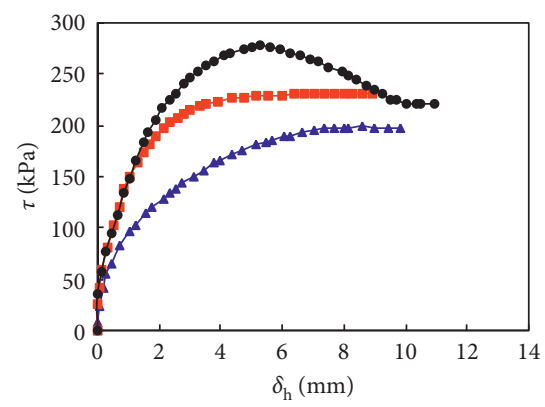

—- Dry density of 1.9

$\longrightarrow$ Dry density of 2.0

$\longrightarrow$ Dry density of 2.15

(f)

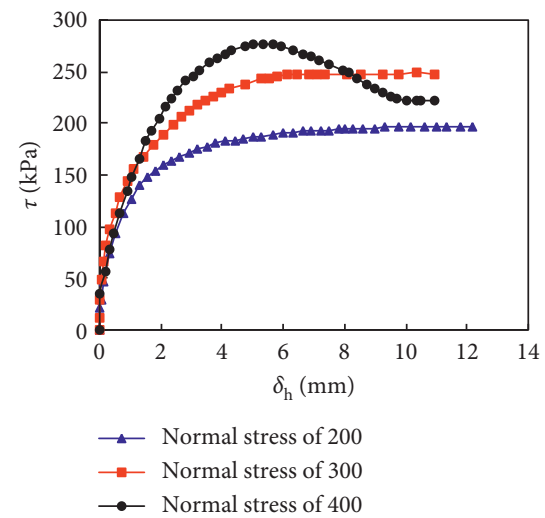

(i)

Figure 5: Relationships between shear stress $(\tau)$ and shear displacement $\left(\delta_{h}\right)$. (a) $\rho_{\mathrm{d}}=2.0 \mathrm{~g} / \mathrm{cm}^{3}, \sigma=200 \mathrm{kPa} .(\mathrm{b}) \rho_{\mathrm{d}}=2.0 \mathrm{~g} / \mathrm{cm}^{3}, \sigma=300 \mathrm{kPa}$. (c) $\rho_{\mathrm{d}}=2.0 \mathrm{~g} / \mathrm{cm}^{3}, \sigma=400 \mathrm{kPa}$. (d) $w=9.0 \%, \sigma=200 \mathrm{kPa}$. (e) $w=9.0 \%, \sigma=300 \mathrm{kPa}$. (f) $w=9.0 \%, \sigma=400 \mathrm{kPa}$. (g) $w=9.0 \%, \rho_{\mathrm{d}}=1.9 \mathrm{~g} / \mathrm{cm}^{3}$. (h) $w=9.0 \%, \rho_{\mathrm{d}}=2.0 \mathrm{~g} / \mathrm{cm}^{3}$. (i) $w=9.0 \%, \rho_{\mathrm{d}}=2.15 \mathrm{~g} / \mathrm{cm}^{3}$.

displacement increasing to $6-10 \mathrm{~mm}$, a creaking sound was heard from the shear plane. Later, the shear stress changed slightly with the increasing shear displacement. Moreover, Figures 5(a)-5(c) indicated that the larger moisture content led to a lower curve slope and a smaller shear stress. But, the effects of dry density and normal stress were opposite to that of moisture content (Figures 5(d)-5(i)). That was to say, the larger the dry density and normal stress, the greater the curve slope and shear stress. And the effect of them on the shear curve was greater than that of moisture content. Furthermore, one direct shear curve showed softening deformation (black line in Figure 5(f)), which may be due to the ice thawing under high normal stress and the particle breakage.

3.1.2. Features of Shear Dilatancy. During the shearing of CGS, the shear surface is usually accompanied by shear dilatancy. The relationships between the vertical displacement $\left(\delta_{\mathrm{v}}\right)$ and the shear displacement $\left(\delta_{h}\right)$ are shown in Figure 6 . For the vertical coordinate, the negative value 


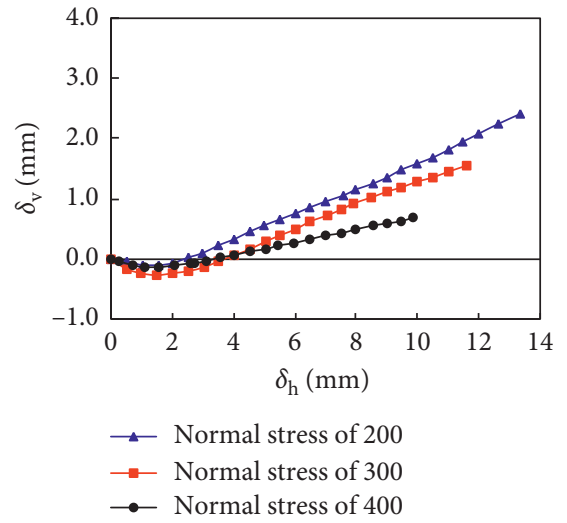

(a)

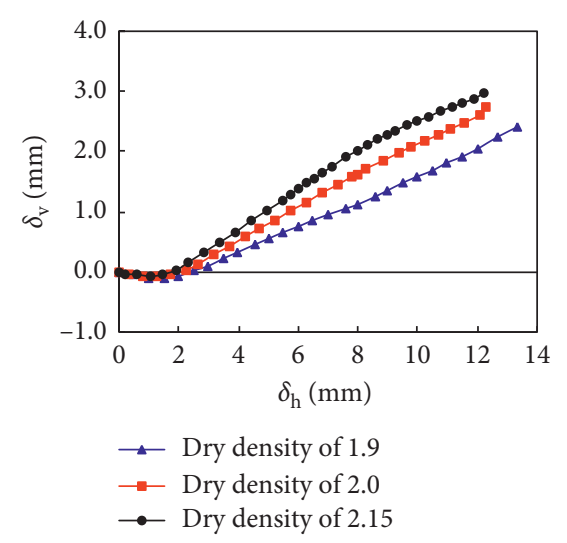

(b)

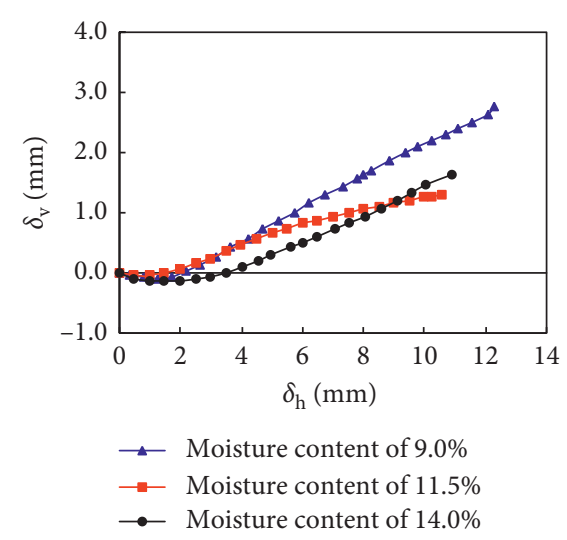

(c)

FIGURE 6: Variation of vertical displacement $\left(\delta_{\mathrm{v}}\right)$ with the increasing shear displacement $\left(\delta_{h}\right)$. (a) $w=9.0 \%, \rho_{\mathrm{d}}=1.9 \mathrm{~g} / \mathrm{cm}^{3}$. (b) $w=9.0 \%$, $\sigma=200 \mathrm{kPa}$. (c) $\rho_{\mathrm{d}}=2.0 \mathrm{~g} / \mathrm{cm}^{3}, \sigma=200 \mathrm{kPa}$.

means the shear shrinkage and the positive one stands for shear dilatancy. In the figure, the vertical displacement decreased firstly and reached a small negative value. Then, the vertical displacement increased considerably with the increase in shear displacement. That is, the freeze-thaw interface in CGS shear shrank at first and shear dilated later. And the shear shrinkage was smaller than the shear dilatancy. However, the curve characteristics were affected by the testing conditions. The larger the normal stress, the greater the volume shrink and the smaller the shear dilatancy. It illustrated that the normal stress has a negative effect on the shear dilatancy of freeze-thaw interface in CGS. The effect of moisture content on the shear dilatancy has a similar pattern to that of normal stress, but the dry density was the opposite.

3.2. Features of Shear Strength of Freeze-Thaw Interface in CGS. Shear strength of soil usually plays an essential role in the stability analysis of slopes and landslides [5, 8]. As shown in Figure 5, the shear stress tended to be stable after a shear displacement of $6.0-10.0 \mathrm{~mm}$ (average value was $8 \mathrm{~mm}$ ). Thus, the shear strength of freeze-thaw interface $\left(\tau_{\mathrm{f}}\right)$ can be defined as the stress at shear displacement of $8.0 \mathrm{~mm}$ in hardening curves or the peak stress in softening curves [23].

3.2.1. Effect of Dry Density on the Shear Strength. The relationship between the shear strength of freeze-thaw interface $\left(\tau_{\mathrm{f}}\right)$ and dry density $\left(\rho_{\mathrm{d}}\right)$ is shown in Figure 7 . With the increase in dry density, the shear strength increased considerably, which is similar to the report by Mouazen et al. [4]. Soil specimens with a moisture content of $9.0 \%$ were taken as an example. The strength at a normal stress of $200 \mathrm{kPa}$ increased by $40.4 \%$ as the dry density increased from $1.9 \mathrm{~g} / \mathrm{cm}^{3}$ to $2.15 \mathrm{~g} / \mathrm{cm}^{3}$. It was due to the compact initial structure of the soil specimen at large dry density. In other words, the interlocking of coarse particles and the connection of fine particles and ice were considerable at this moment. Besides, this increasing rate was also affected slightly by normal stress and moisture content. The larger the normal stress was, the greater the increasing rate was. But the increasing rate decreased with the increase in moisture content.

3.2.2. Effect of Moisture Content on the Shear Strength. Figure 8 shows that the shear strength of freeze-thaw interface decreased with the increase in moisture content. The shear strength of interface at a dry density of $1.9 \mathrm{~g} / \mathrm{cm}^{3}$ and a normal stress of $200 \mathrm{kPa}$ decreased by $19.7 \%$ with the increase in moisture content (from $9.0 \%$ to $14.0 \%$ ). The reason was that the soil specimens near the optimum moisture content were easily compacted and had high shear strength, although the situation was the opposite when soil tended to be saturated. It was because ice and unfrozen water dynamically coexisted in the freeze-thaw interface, and the larger the moisture content, the more the unfrozen water. The coupling effect of the cementation of ice and the lubrication of unfrozen water in the freeze-thaw interface played a complex role in shear strength. Moreover, the increasing normal stress and dry density also increased the decreasing rate of shear strength in Figure 8.

3.2.3. Effect of Normal Stress on the Shear Strength. As shown in Figure 9, the shear strength of freeze-thaw interface increased by $35.2 \%-43.1 \%$ with the increase in normal stress (from 200 to $400 \mathrm{kPa}$ ). The effect of normal stress on the shear strength was similar to that of dry density. During the entire shear test process, the normal stress reduced the soil porosity and particle spacing, increased the dry density, and enhanced the interlocking among particles. Then, the soil structure tended to be dense, and the stress state of particles increased, which led to an increase in shear strength and high capability of soil specimens to resist shear deformation.

3.3. Features of Strength Parameters of Freeze-Thaw Interface in CGS. According to the test results (Figure 10), the relationship between the shear strength of freeze-thaw interface and normal stress could be described by a linear function, as follows: 


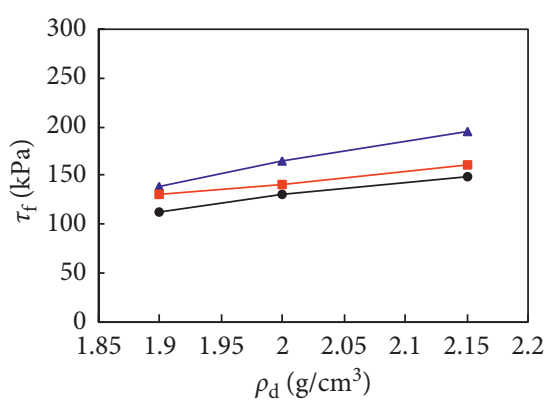

ـ Moisture content of $9.0 \%$

$\rightarrow$ Moisture content of $11.5 \%$

$\rightarrow$ Moisture content of $14.0 \%$

(a)

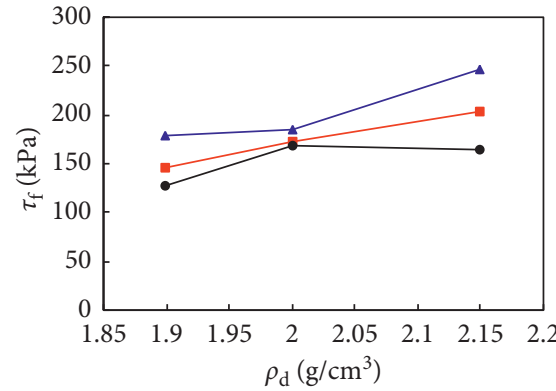

$\rightarrow$ Moisture content of $9.0 \%$

$\rightarrow$ Moisture content of $11.5 \%$

$\rightarrow$ Moisture content of $14.0 \%$

(b)

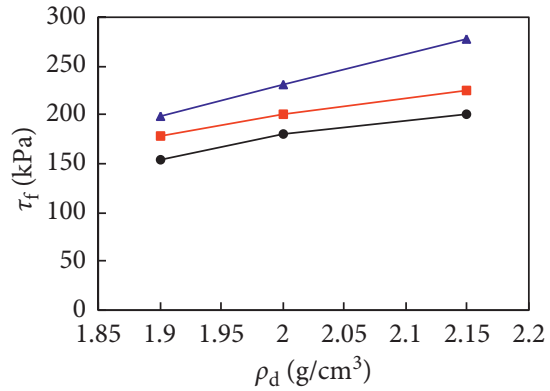

$\rightarrow$ Moisture content of $9.0 \%$

$\rightarrow$ Moisture content of $11.5 \%$

$\rightarrow$ Moisture content of $14.0 \%$

(c)

Figure 7: Relationship between shear strength $\left(\tau_{\mathrm{f}}\right)$ and dry density $\left(\rho_{\mathrm{d}}\right)$. (a) $\sigma=200 \mathrm{kPa}$. (b) $\sigma=300 \mathrm{kPa}$. (c) $\sigma=400 \mathrm{kPa}$.

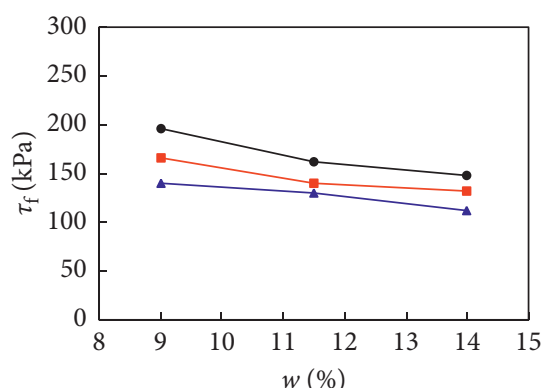

$\rightarrow$ Dry density of 1.9

$\rightarrow$ Dry density of 2.0

$\rightarrow$ Dry density of 2.15

(a)

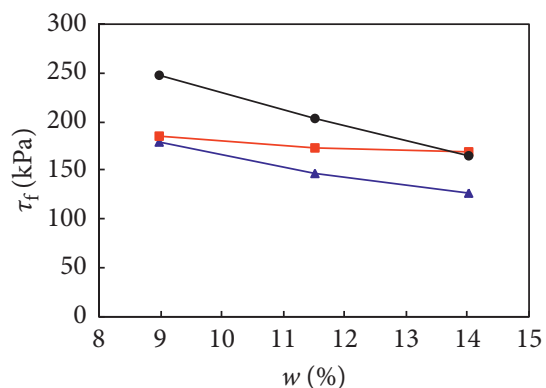

$\rightarrow$ Dry density of 1.9

$\rightarrow$ Dry density of 2.0

- Dry density of 2.15

(b)

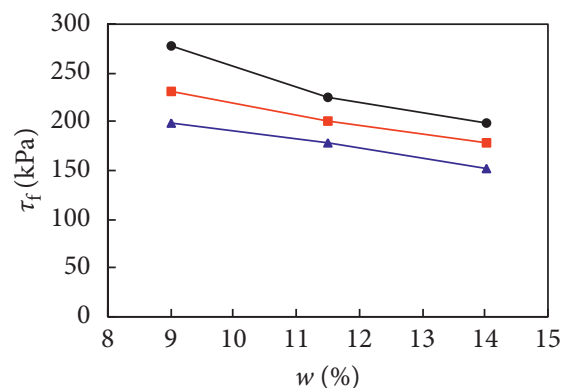

$\rightarrow$ Dry density of 1.9

$\rightarrow$ Dry density of 2.0

- D Dry density of 2.15

(c)

Figure 8: Variations of shear strength $\left(\tau_{\mathrm{f}}\right)$ with moisture content $(w)$. (a) $\sigma=200 \mathrm{kPa}$. (b) $\sigma=300 \mathrm{kPa}$. (c) $\sigma=400 \mathrm{kPa}$.

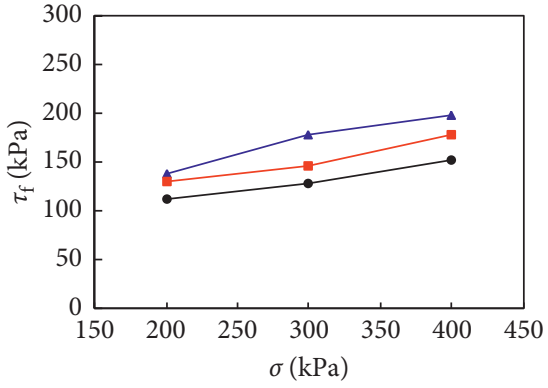

$\rightarrow$ Moisture content of $9.0 \%$

$\rightarrow$ Moisture content of $11.5 \%$

$\rightarrow$ Moisture content of $14.0 \%$

(a)

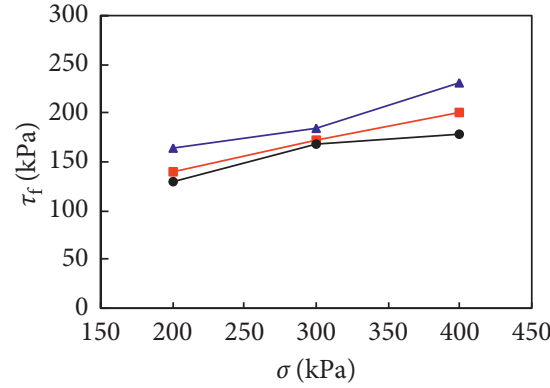

$\longrightarrow$ Moisture content of $9.0 \%$

$\rightarrow-$ Moisture content of $11.5 \%$

$\longrightarrow$ Moisture content of $14.0 \%$

(b)

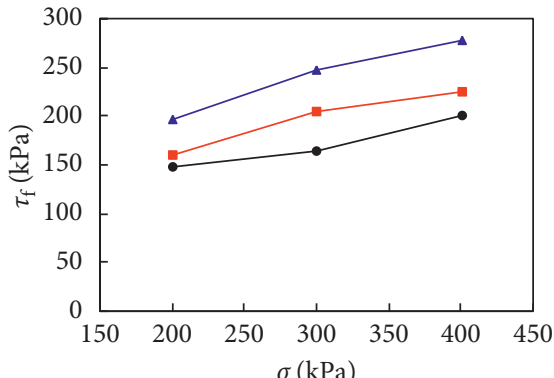

$\rightarrow$ Moisture content of $9.0 \%$

$\rightarrow$ Moisture content of $11.5 \%$

$\rightarrow$ Moisture content of $14.0 \%$

(c)

FIgURE 9: Relationship between shear strength $\left(\tau_{\mathrm{f}}\right)$ and normal stress $(\sigma)$. (a) $\rho_{\mathrm{d}}=1.9 \mathrm{~g} / \mathrm{cm}^{3}$. (b) $\rho_{\mathrm{d}}=2.0 \mathrm{~g} / \mathrm{cm}^{3}$. (c) $\rho_{\mathrm{d}}=2.15 \mathrm{~g} / \mathrm{cm}^{3}$.

$$
\tau_{f}=k \cdot \sigma+b,
$$

where $k$ is the slope of curve and $b$ is the curve intercept. Regression analysis showed that the coefficient of determination $\left(R^{2}\right)$ ranged from 0.91 to 0.99 . It illustrated that this linear function could well describe their relationship. Hence, the strength parameters of freeze-thaw interface could be calculated by the following Mohr-Coulomb formula: 


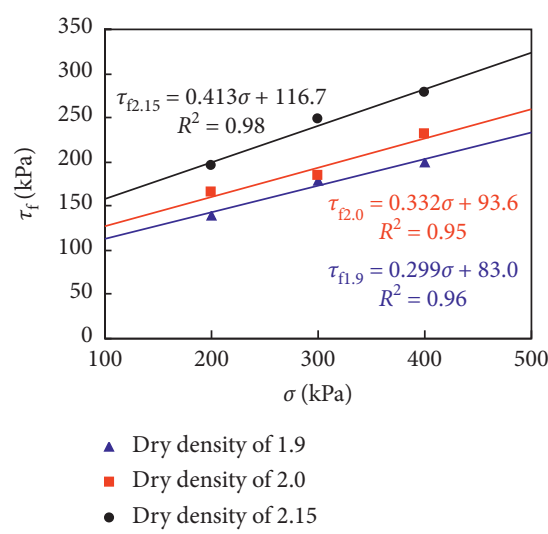

(a)

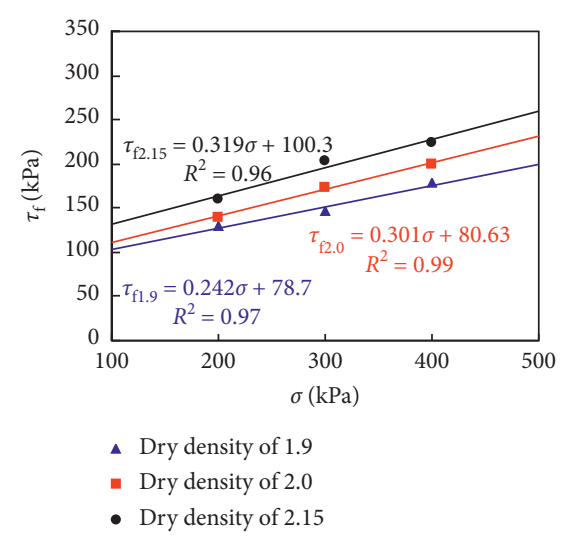

(b)

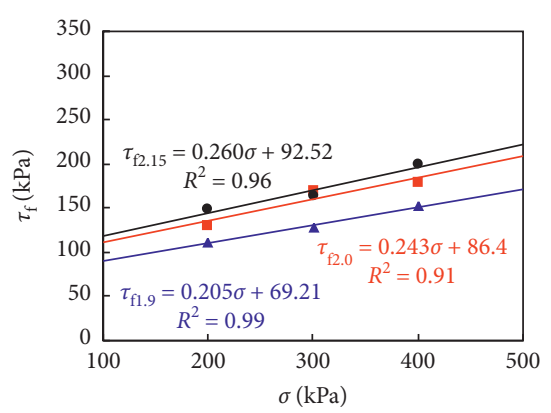

- Dry density of 1.9

- Dry density of 2.0

- Dry density of 2.15

(c)

Figure 10: Shear strength composition of freeze-thaw interface in CGS. (a) $w=9.0 \%$. (b) $w=11.5 \%$. (c) $w=14.0 \%$.

$$
\tau_{f}=\tau_{c}+\tau_{\varphi}=\sigma \cdot \tan \varphi+c
$$

where $\tau_{c}$ is the cohesive strength, $\tau_{\varphi}$ is the frictional strength, $c$ is the cohesion, and $\varphi$ is the internal friction angle. In this test, the freeze-thaw interface of soil specimen was mainly composed of fine and coarse particles and pore water and ice. Generally speaking, the ice has a certain cohesive force and its friction could be negligible. But, that of coarse particles is the opposite. Thus, the cohesion of the freezethaw interface came not only from the clay particles but also from the pore ice. The frictional strength of specimens was controlled by both fine and coarse particles. That is to say, the shear parameters $(c$ and $\varphi$ ) of specimens were comprehensive value.

3.3.1. Variations of Cohesion. Variations of the cohesion in freeze-thaw interface $(c)$ are shown in Figure 11. With the increase in dry density $\left(1.9-2.5 \mathrm{~g} / \mathrm{cm}^{3}\right)$, the cohesion of interface increased by $27.4 \%-40.6 \%$. Increasing dry density resulted in a decrease in the porosity of soil and further enhanced the connection of fine particles and the interlocking of coarse particles. Besides, the cohesion from ice in interface also increased due to the decreasing particle spacing and the increasing volume proportion of pore water. As shown in Figure 11(b), the cohesion decreased by $7.8 \%-$ $20.7 \%$ with the increase in moisture content (from $9 \%$ to 14\%). Mouazen et al. [4] also observed this phenomenon in thawed soil. It was due to the double influence of water-ice mixtures in the freeze-thaw interface. On the one hand, the enhanced lubrication and softening effects of water on the particles led to the decrease of cohesion. On the other hand, the connection of ice exerted an opposite effect.

3.3.2. Variations of Internal Friction Angle. Figure 12 shows the variations of the internal friction angle $(\varphi)$ of freeze-thaw interface. In the figure, the internal friction angle increased with the increase in dry density, but it decreased with the increasing moisture content. When the dry density increased from 1.9 to $2.15 \mathrm{~g} / \mathrm{cm}^{3}$, the angle increased by $25.9 \%-34.9 \%$. A dense soil structure led to a large interlocking of coarse particles and friction of particles due to large dry density, and the internal friction angle then increased. In addition, the angle decreased by $25.8 \%-35.2 \%$ with the increase in the moisture content $(9.0 \%-14.0 \%)$. In the freeze-thaw interface, the internal friction angle of ice usually was ignored. So, the lubrication and softening effect of water on the particles played a major role in the changes of the internal friction angle. Besides, the heat produced by the friction of particles would result in the ice melting to further affect the variations in internal friction angle.

\section{Discussion}

4.1. Shear Process and Particle Movement of Shear Interface. Many studies indicate that the shear strength of CGS in room temperature depends on the ratio between the coarse particles and fine particles, which determine the soil structure and shear mechanism $[16,23]$.

In this study, the shear strength of freeze-thaw interface in CGS mainly depended on that of coarse particles and the cementation of ice. The fine particles filled parts of the soil pores or covered the surface of coarse particles. The schematic diagram of the shearing process of the freeze-thaw interface in CGS is shown in Figure 13. Various zones distributed on each side of the freeze-thaw interface had significant differences in physical and mechanical properties. In the thawed zone, the shear strength mainly came from the apparent cohesion and friction of coarse particles. However, in addition to these actions, the cohesion of ice occurred in the frozen zone. The freeze-thaw interface, a phase transition zone of ice and water, contained all these roles. The boundary constraint of particles in the interface near the thawed zone was weaker than that near the frozen zone. Particle slippage and rotation easily occurred in the interface during the shearing process (Figures 13(b) and 13(c)). The amplitude of particle movement in the interface near the frozen zone was relatively small, and the deformation showed a certain extent of brittleness, which had been confirmed by Wang et al. [23] and De Guzman et al. [28]. Under a large normal stress, some needle- and flake-like coarse particles would break (Figure 13(d)), and the pressure 


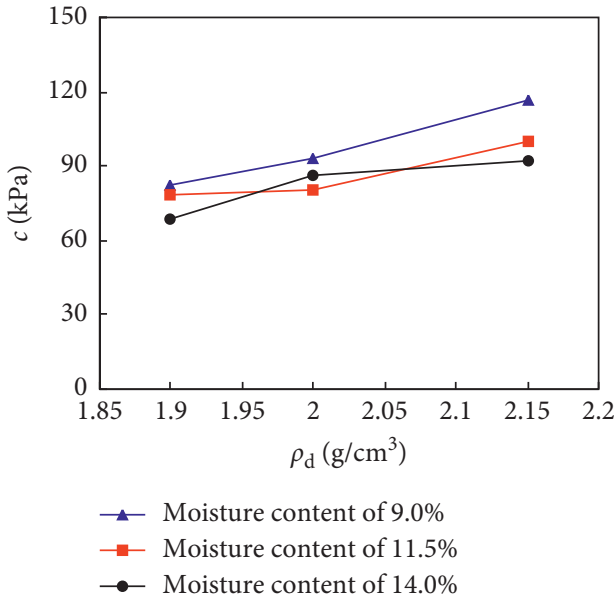

(a)

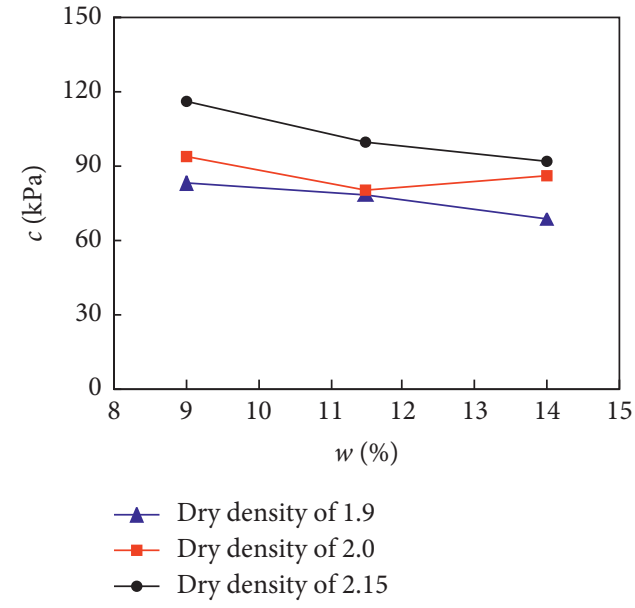

(b)

Figure 11: (a) Variations of cohesion $(c)$ with dry density $\left(\rho_{\mathrm{d}}\right)$. (b) Variations of cohesion $(c)$ with moisture content $(w)$.

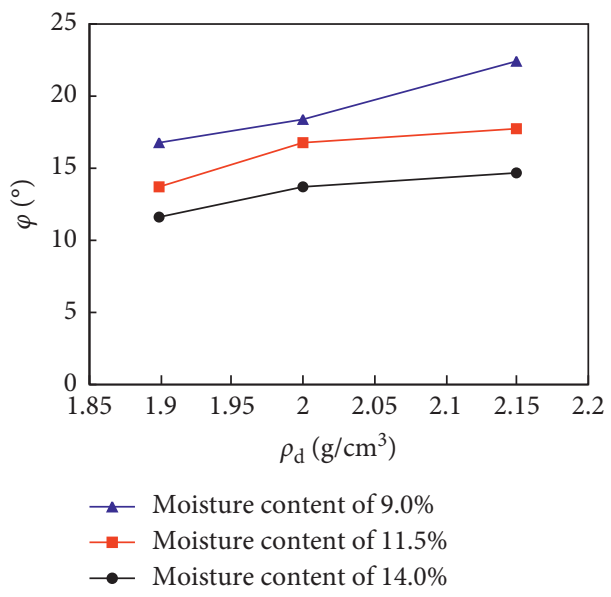

(a)

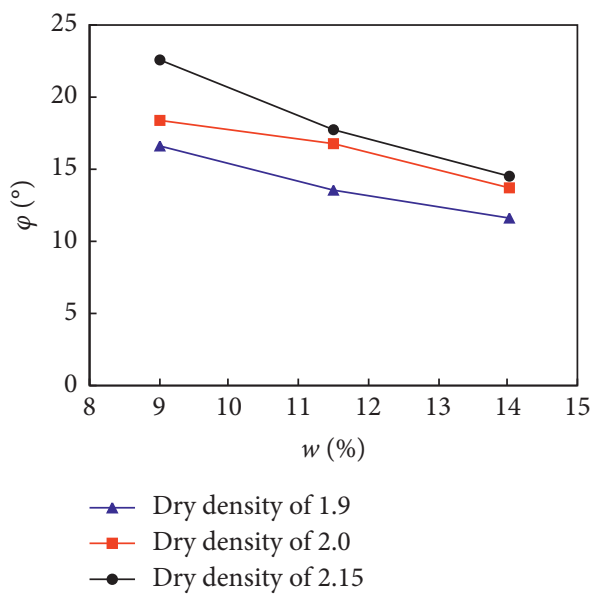

(b)

Figure 12: (a) Relationships between internal friction angle $(\varphi)$ and dry density $\left(\rho_{\mathrm{d}}\right)$. (b) Relationships between internal friction angle $(\varphi)$ and moisture content $(w)$.

melting of ice might occur in the freeze-thaw interface, which weakened the interlocking of coarse particles and ice cohesion.

The cohesion action from ice played a controlling role in the test beginning, which resulted in the initial vertical section of the direct shear curve in Figure 5. With the further shearing, the cementation of ice was damaged. Following that, the rotation and slippage of particles occur and even some fracture of coarse particles occur accompanied with a creaking sound. At that time, the friction and interlocking of particles started work and the curve performed as nonlinearly changes. When the particle movement reached an equilibrium state in the interface, the shear stress changed very slightly. CGS. During the formation and shearing of the freeze-thaw interface, water migration always occurs in the interface of CGS. That is, the pore water moves to the freezing front when the soil sample freezes [3]. The final result is the variation of moisture content in different positions of soil specimens. After each shear test, the moisture content in the middle position of lower shear box (frozen soil, $H=5 \mathrm{~cm}$ ), shear plane (i.e., freeze-thaw interface, $H=10 \mathrm{~cm}$ ), and the middle of the upper box (thawed soil, $H=15 \mathrm{~cm}$ ) were tested by drying method and are plotted in Figure 14.

In this figure, the moisture contents in the lower box and freeze-thaw interface were larger than the initial moisture content (green line in Figure 14). However, the moisture content in the upper shear box was reduced. It was owing to the water migration in the CGS containing fine particles under negative temperature, which was also reported by Konrad [1] and Li et al. [18]. When the temperature of the lower box reduced below $0^{\circ} \mathrm{C}$, water in soil moved to the freezing front and the moisture content of the lower box 


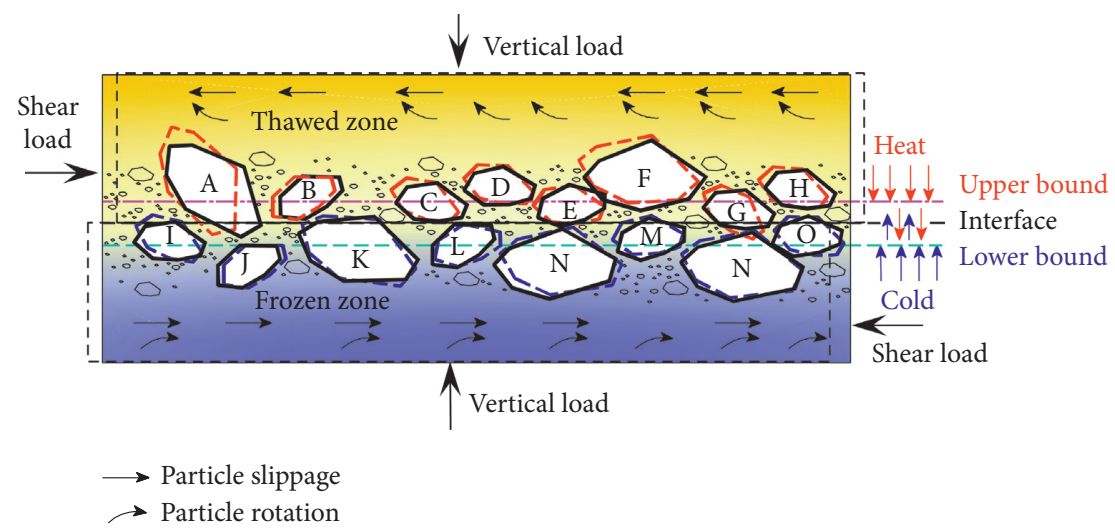

(a)

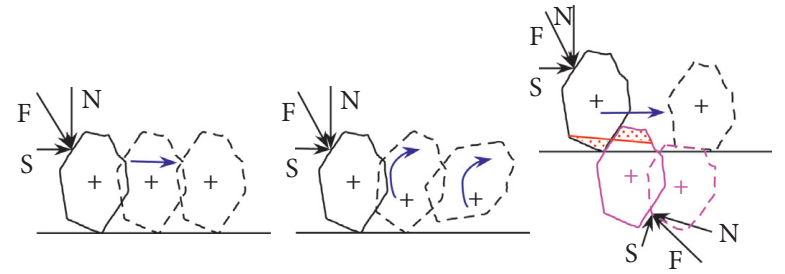

(b)

(c)

(d)

Figure 13: Particle movement in freeze-thaw interface during the shearing process. (a) Shear process. (b) Particle slippage. (c) Particle rotation. (d) Particle breakage.

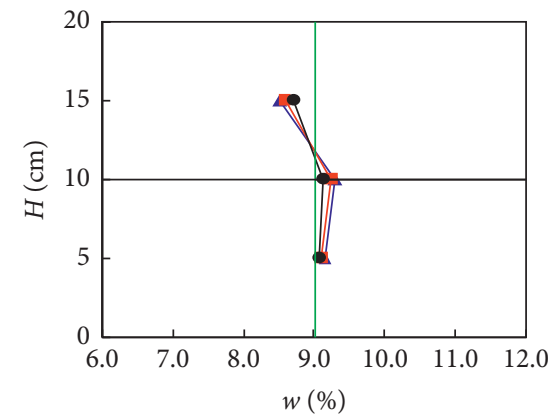

$\_$Dry density of 1.9

$\rightarrow$ Dry density of 2.0

$\rightarrow$ Dry density of 2.15

(a)

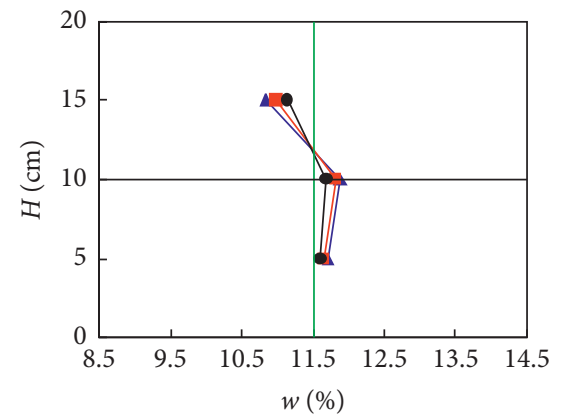

$\_$Dry density of 1.9

$\rightarrow$ Dry density of 2.0

$\rightarrow$ Dry density of 2.15

(b)

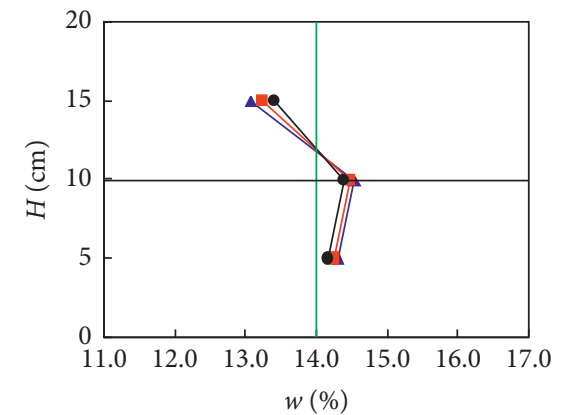

^ Dry density of 1.9

$\rightarrow$ Dry density of 2.0

$\rightarrow$ Dry density of 2.15

(c)

FIGURe 14: Distribution of moisture content in different positions of soil specimen. (a) $w=9.0 \%$. (b) $w=11.5 \%$. (c) $w=14.0 \%$.

increased. When the freeze front moved to the shear plane (freeze-thaw interface), the position movement stopped, but the heat exchange and ice-water phase transition always existed in the freeze-thaw interface. Water accumulated incessantly to the freeze-thaw interface because of the temperature gradient, which led to a larger moisture content of interface. Besides, the moisture content in the upper box (thawed soil) was smaller than the initial moisture content because of the removal of pore water.

4.3. Effect of Ice on Strength of Freeze-Thaw Interface. Compared with thawed soil, the difference of freeze-thaw interface in CGS was that a part of water freezes into ice and the unfrozen water and ice were coexistent $[18,29]$. Figure 15 shows the relationship of shear stress and shear displacement of both thawed CGS and freeze-thaw interface. In this figure, the shear stress of freeze-thaw interface is always larger than that of thawed soil at the same shear displacement. It illustrated that the ice in the interface plays an essential role during the whole shearing process. To describe the effect of ice in freeze-thaw interface, a quantitative parameter can be defined as follows:

$$
\eta=\frac{\tau_{i}}{\tau_{u}}
$$

where $\eta$ is the quantitative parameter, $\tau_{i}$ is the shear stress of freeze-thaw interface, and $\tau_{u}$ is the shear stress of thawed soil. 


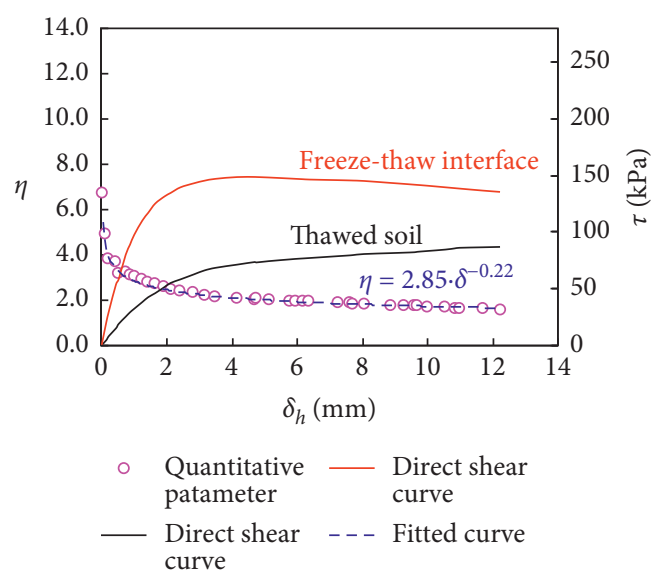

(a)

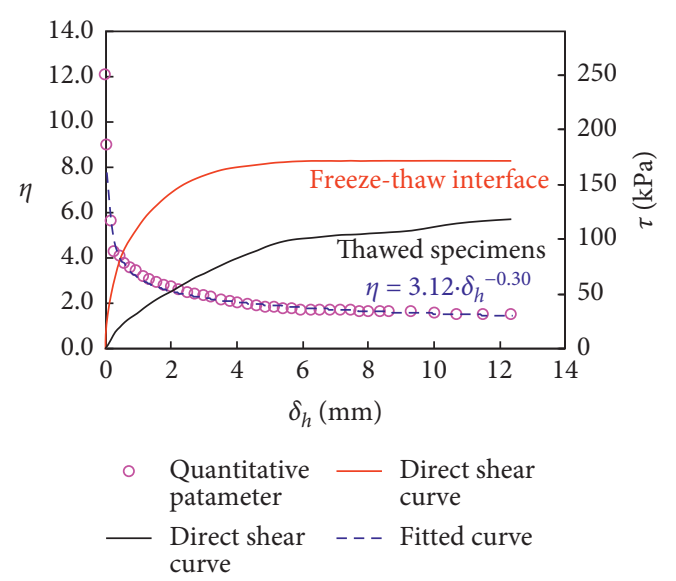

(b)

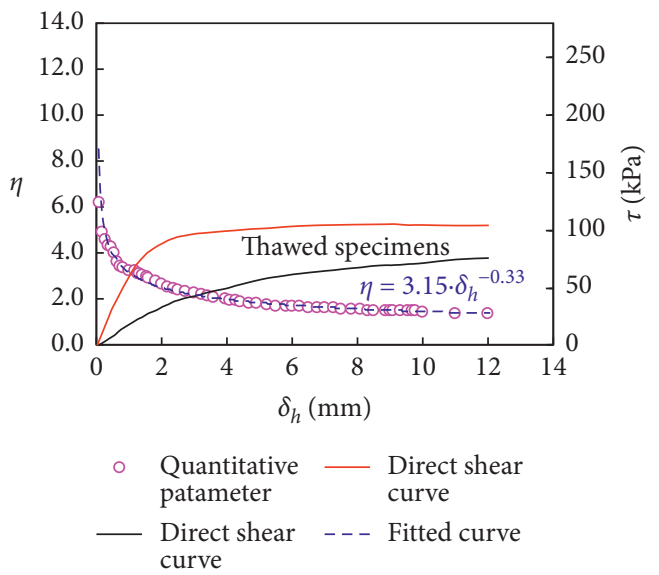

(c)

Figure 15: Variation of quantitative parameter $(\eta)$ with shear displacement $\left(\delta_{h}\right)$. (a) $w=11.5 \%, \rho_{\mathrm{d}}=2.0 \mathrm{~g} / \mathrm{cm}^{3}, \sigma=200 \mathrm{kPa}$. (b) $w=11.5 \%$, $\rho_{\mathrm{d}}=2.0 \mathrm{~g} / \mathrm{cm}^{3}, \sigma=300 \mathrm{kPa}$. (c) $w=14.0 \%, \rho_{\mathrm{d}}=1.9 \mathrm{~g} / \mathrm{cm}^{3}, \sigma=200 \mathrm{kPa}$.

According to (3), a large shear stress of freeze-thaw interface and a low shear stress of thawed soil would lead to a large quantitative parameter. That is, the effect of ice on the interface strength was considerable. The variations of the parameter $(\eta)$ with shear displacement $\left(\delta_{h}\right)$ are shown in Figure 15 . In the figure, the parameter initially decreased rapidly and then decreased slowly before $8 \mathrm{~mm}$, and then it reduced slightly. The relationship between the parameter and shear displacement can be expressed by a power function, namely,

$$
\begin{aligned}
& \eta=K \cdot \delta_{h}^{n}, \\
& \tau_{i}=K \cdot \delta_{h}^{n} \cdot \tau_{u},
\end{aligned}
$$

where $K$ is the modulus number and $n$ represents the modulus exponent; both are dimensionless numbers.

The model parameters of (5) at different moisture contents $(w)$, dry densities $\left(\rho_{\mathrm{d}}\right)$, and normal stresses $(\sigma)$ are listed in Table 2. Compared with the test results, the coefficient of determination ( $R$-squared) of model ranged from 0.98 to 0.99 , which illustrated the notion that the proposed model could well describe their relationship.
TABLE 2: Model parameters of different soil specimens.

\begin{tabular}{lccccc}
\hline & Soil specimen & \multicolumn{4}{c}{$\begin{array}{c}\text { Model } \\
\text { parameters }\end{array}$} \\
$\begin{array}{l}\text { Moisture } \\
\text { content w }(\%)\end{array}$ & $\begin{array}{c}\text { Dry density } \\
\left(\rho_{\mathrm{d}} / \mathrm{g} \cdot \mathrm{cm}^{-3}\right)\end{array}$ & $\begin{array}{c}\text { Normal stress } \\
(\sigma / \mathrm{kPa})\end{array}$ & $K$ & $n$ & \\
\hline 11.5 & 2.0 & 200 & 2.85 & -0.22 & 0.98 \\
11.5 & 2.0 & 300 & 3.12 & -0.30 & 0.98 \\
14.0 & 1.9 & 200 & 3.15 & -0.33 & 0.99 \\
\hline
\end{tabular}

The changes of quantitative parameter $(\eta)$ in Figure 15 were due to the ice cohesion existing in the freeze-thaw interface during the whole shearing process. With the increase in shear displacement, the shear damage of ice could lead to a decrease in the ice cohesion. Moreover, the ice melting caused by the frictional heat of particles also aggravates this decrease. However, the quantitative parameter at the stable stage tended to be 1.4-1.9, which was larger than the unit number of 1.0 . This finding illustrated the notion that the ice always existed in the freeze-thaw interface of soil specimens. And the effect of ice cohesion always played a role during the entire shearing process. It was related to the long-standing dynamic transformation between water and ice in the freeze-thaw interface. 


\section{Conclusions}

(1) The freeze-thaw interface in CGS mainly performed as hardening deformation in the shear process, which was affected significantly by the three testing factors. The shear strength of interface increased with the increasing dry density and normal stress, but the effect of moisture content was the opposite.

(2) The cohesion of freeze-thaw interface in CGS increased by $27.4 \%-40.6 \%$ with the increasing dry density but decreased by $7.8 \%-20.7 \%$ with the moisture content. The internal friction angle also increased and reduced with the increase in dry density and moisture content, respectively. The shear properties of freeze-thaw interface of CGS can be used as reference for practical engineering.

(3) The shear strength of freeze-thaw interface in CGS depends on the strength of fine particles, cementation of ice, and interlocking of coarse particles. During the shearing, the particle slippage and rotation even fracture occurred in the interface.

(4) At test conditions, the water migration in the freezethaw interface in CGS led to a higher moisture content of interface than in other places. But compared with the thawed soil, the ice always existed and worked for the strength of freeze-thaw interface in CGS, and the effect of ice can be described by a proposed parameter.

\section{Data Availability}

The data used to support the findings of this study are available from the corresponding author upon request.

\section{Conflicts of Interest}

The authors declare that they have no conflicts of interest regarding the publication of this paper.

\section{Acknowledgments}

This study was supported by the Second Tibetan Plateau Scientific Expedition and Research (STEP) Program (Grant no. 2019QZKK0905), the Key Scientific Research Project of China Gold Group (Grant no. 2016ZGHJ/XZHTL-YQSC26), and the funding from the Department of Transportation of Gansu Province (Grant no. 2017-008). These supports are greatly appreciated.

\section{References}

[1] J. M. Konrad, "Freezing-induced water migration in compacted base-course materials," Canadian Geotechnical Journal, vol. 45, no. 7, pp. 895-909, 2008, https://www. researchgate.net/deref/http\%3A\%2F\%2Fdx.doi.org\%2F10. 1139\%2FT08-024.

[2] W. Ma, G. D. Cheng, and Q. B. Wu, "Construction on permafrost foundations: lessons learned from the Qinghai-Tibet railroad," Cold Regions Science and Technology, vol. 59, no. 1, pp. 3-11, 2009.
[3] J. Xu, S. H. Wang, Z. Q. Wang et al., "Heat transfer and water migration in loess slopes during freeze-thaw cycling in Northern Shaanxi, China," International Journal of Civil Engineering, vol. 16, no. 11, pp. 1591-1605, 2018.

[4] A. M. Mouazen, H. Ramon, and J. D. Baerdemaeker, "SW-soil and water: effects of bulk density and moisture content on selected mechanical properties of sandy loam soil," Biosystems Engineering, vol. 83, no. 2, pp. 217-224, 2002.

[5] Y. C. Cheng, Q. Ge, and F. He, "Experimental research on critical depth of slip surface of soil slope in seasonal frozen area," Rock and Soil Mechanics, vol. 31, no. 4, pp. 1042-1046, 2010.

[6] Y. L. Qu, W. K. Ni, F. J. Niu, Y.-H. Mu, G.-L. Chen, and J. Luo, "Mechanical and electrical properties of coarse-grained soil affected by cyclic freeze-thaw in high cold regions," Journal of Central South University, vol. 27, no. 3, pp. 853-866, 2020.

[7] J. Xu, Z. Q. Wang, J. W. Ren, S.-H. Wang, and L. Jin, "Mechanism of slope failure in loess terrains during spring thawing," Journal of Mountain Science, vol. 15, no. 4, pp. 845-858, 2018.

[8] F. J. Niu, G. D. Cheng, W. K. Ni, and D. Jin, "Engineeringrelated slope failure in permafrost regions of the QinghaiTibet Plateau," Cold Regions Science and Technology, vol. 42, no. 3, pp. 215-225, 2005.

[9] J. W. Zhou, P. Cui, and M. H. Hao, "Comprehensive analyses of the initiation and entrainment processes of the 2000 Yigong catastrophic landslide in Tibet, China," Landslides, vol. 13, pp. 39-54, 2016.

[10] A. T. DeGaetano, M. D. Cameron, and D. S. Wilks, "Physical simulation of maximum seasonal soil freezing depth in the united states using routine weather observations," Journal of Applied Meteorology and Climatology, vol. 40, no. 3, pp. 546-555, 2001.

[11] I. Kennedy and B. Sharratt, "Model comparisons to simulate soil frost depth," Soil Science, vol. 163, no. 8, pp. 636-645, 1998.

[12] T. Hirota, Y. Iwata, M. Hayashi et al., "Decreasing soil-frost depth and its relation to climate change in Tokachi, Hokkaido, Japan," Journal of the Meteorological Society of Japan, vol. 84, no. 4, pp. 821-833, 2006.

[13] X. Y. Xu, J. K. Ding, and A. J. Lou, "Determining the longterm shear strength at the frozen-unfrozen interface," Journal of Harbin University of Civil Engineering and Architecture, vol. 25, no. 3, pp. 37-42, 1992.

[14] Y. C. Cheng, P. Jiang, and Q. Ge, "Experimental research on the shear strength parameters between the freezing and thawing surface of soil slope in seasonal frozen regions," in Proceedings of the 11th International Conference of Chinese Transportation Professionals (ICCTP), Nanjing, China, August 2011.

[15] Q. Ge, H. Wu, and Y. F. Gong, "Research on the soil slope stability based on soil strength deterioration in seasonal frozen areas," Advanced Materials Research, vol. 243, pp. 4270-4273, 2011.

[16] Q. Gao, Z. Wen, D. Y. Wang et al., "Study on the instability process of slopes in permafrost regions by direct shear test of freezing-thawing interface," Rock and Soil Mechanics, vol. 39, no. 8, pp. 2814-2822, 2018.

[17] R. S. Anderson, "Modeling the tor-dotted crests, bedrock edges, and parabolic profiles of high alpine surfaces of the wind river range, Wyoming," Geomorphology, vol. 46, no. 1-2, pp. 35-58, 2002.

[18] A. Y. Li, F. J. Niu, H. Zheng, S. Akagawa, Z. Lin, and J. Luo, "Experimental measurement and numerical simulation of 
frost heave in saturated coarse-grained soil," Cold Regions Science and Technology, vol. 137, pp. 68-74, 2017.

[19] T. L. Wang, Z. R. Yue, C. Ma, and Z. Wu, "An experimental study on the frost heave properties of coarse grained soils," Transportation Geotechnics, vol. 1, pp. 137-144, 2014.

[20] N. A. Beier and D. C. Sego, "Cyclic freeze-thaw to enhance the stability of coal tailings," Cold Regions Science and Technology, vol. 55, pp. 278-285, 2009.

[21] J. L. Qi, W. Ma, and C. X. Song, "Influence of freeze-thaw on engineering properties of a silty soil," Cold Regions Science and Technology, vol. 53, pp. 397-404, 2008.

[22] Y. L. Qu, G. L. Chen, F. J. Niu, W. K. Ni, Y. Mu, and J. Luo, "Effect of freeze-thaw cycles on uniaxial mechanical properties of cohesivecoarse-grained soils," Journal of Mountain Science, vol. 16, no. 1, pp. 2159-2170, 2019.

[23] Q. Z. Wang, X. X. Zhu, J. K. Liu, and P. Lu, "Experimental study on direct shear tests of coarse-grained fillings of highspeed railway subgrade in cold region," Journal of the China Railway Society, vol. 35, no. 8, pp. 102-109, 2016.

[24] J. K. Liu, D. Chang, and Q. M. Yu, "Influence of freeze-thaw cycles on mechanical properties of a silty sand," Engineering Geology, vol. 210, pp. 23-32, 2016.

[25] X. B. Chen, J. S. Zhang, and Z. Y. Li, "Shear behaviour of a geogrid-reinforced coarse-grained soil based on large-scale triaxial tests," Geotextiles and Geomembranes, vol. 42, no. 4, pp. 312-328, 2014.

[26] T. Nakao and S. Fityus, "Direct shear testing of a marginal material using a large shear box," Geotechnical Testing Journal, vol. 31, no. 5, pp. 393-403, 2008.

[27] J. K. Liu, P. Lv, Y. H. Cui, and J. Liu, "Experimental study on direct shear behavior of frozen soil-concrete interface," Cold Regions Science and Technology, vol. 104, pp. 1-6, 2014.

[28] E. M. B. De Guzman, D. Stafford, M. C. Alfaro, G. Dore, and L. U. Arenson, "Large-scale direct shear testing of compacted frozen soil under freezing and thawing conditions," Cold Regions Science and Technology, vol. 151, pp. 138-147, 2018.

[29] Y. Yamamoto and S. M. Springman, "Three- and four-point bending tests on artificial frozen soil samples at temperatures close to $0^{\circ} \mathrm{C}$," Cold Regions Science and Technology, vol. 134, pp. 20-32, 2017. 